\title{
The Relation between the Traces of Fish School Recorded by the Net Recorder and the Catch of Trawl Fishing in the Northern Pacific Ocean*
}

\author{
Masuo KaTo and Shigeki NoNAKA** \\ (Received November 22, 1967)
}

Net recorder is a wireless remote-controlled Fish finder for bottom trawlings, in which the signals of underwater information are conveyed by ultrasonic waves. Fig. 1 shows its principle and construction. It mainly consists of transmitter, receiver and indicator units, and transmitter unit is separated into two parts, i.e. detector and transmitter parts. The detector part fixed on the head rope of the net emits ultrasonic waves vertically and receive the signals, which are fed to the transmitter part. The transmitter part directed to a fishing boat emits the signals to the receiver towed by the boat, and the indicator mounted on the bridge records the signals on the recording paper. Thus, the paper indicates height of the net mouth, the net depth,

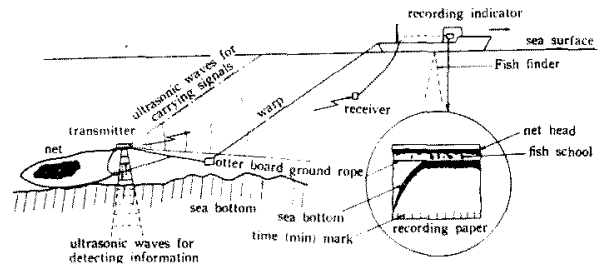

Fig. 1. Principle and constitution of Net recorder. fish school entering the net and the conditions of the damaged net, etc.

Of these observations obtained by Net recorder, it is the purpose of this report to show the relation between the recordings of fish school having entered the net and the haul of fish correspond to the recordings, based on the data actually gathered in the Northern Pacific Ocean bottom fishing grounds.

\section{Method of Survey}

This is on the basis of the data obtained at the time of the actual trawlings by the 72nd Akebono-Maru which belongs to Nichiro Gyogyo Co., Ltd. and Fig. 2 shows fishing grounds and fishing dates.

As methods of survey, fish traces per haul of fish recorded on Net recorder were integrated, and then the integrated area and the haul of fish correspond to the area were compared.

* The outline of this article was reported at the Annual Meeting of the Japanese Society of Scientific Fisheries on 2nd of April, 1967.

** Furuno Electric Co., Ltd. Towa Building, No. 5, 4-chome, Yaesu, Chuo-ku, Tokyo (加藤増 夫・野中茂樹, 古野電気株式会社). 


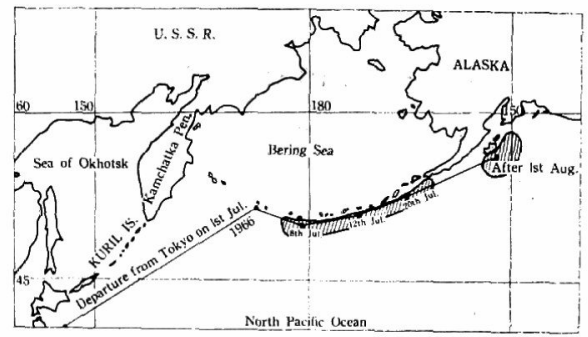

Fig. 2. Fishing grounds and dates operated by the 72nd Akebono-Maru.

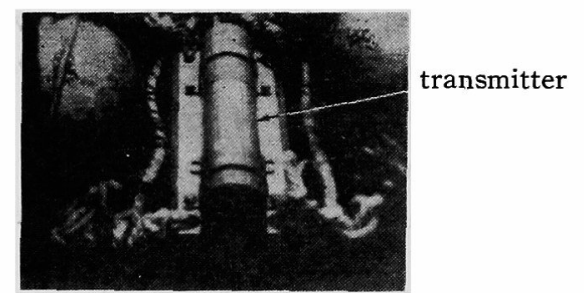

Fig. 4. Transmitter fixed at the center of the head rope of the net.

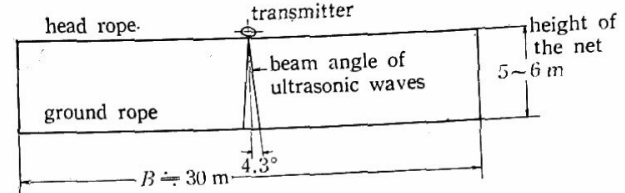

Fig. 3. Cross section of the net mouth and position of transmitter in operation.

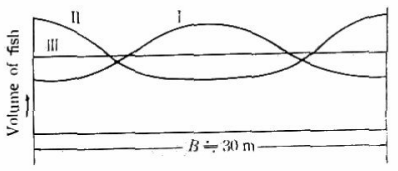

Fig. 5. Presupposition for formation of fish school entering the net mouth.

Fig. 3 shows a cross section of the net opening in operation. Many recordings show height of the net being kept 5 to 6 meters. At the center of the head rope of the net, transmitter unit was fixed (see Fig. 4). As directivity $\left(R_{S R}\right)$ of ultrasonic pulses $(200 \mathrm{Kc} / \mathrm{s})$ emitted from the detector part is nearly 4.3 degrees $\left(=\theta_{S R} \frac{1}{2}\right)$ measured at half power point of sound pressure, they can detect only a small portion of the net mouth. Consequently, it is difficult to detect all the fish school entering the net. Further, the sectional distribution form of fish school varies complicatedly during fish school enters the net mouth. Supposing that the amount of fish school having entered the net is constant, as shown in Fig. 5, the following are considered: Type I indicates fish school passes through the middle of the net mouth in mass formation and Type II indicates fish school enters the net at wings in crowds. It however is regarded as appropriate that as seen in Type III, fish school enters the net in rectangular formation, which is the presupposition in this report.

Since the ultrasonic pulses $(50 \mathrm{Kc} / \mathrm{s})$ emitted from transmitter part are frequency modulated, they can travel the long distance without being affected by noises and being attenuated too much. But when the net is lowered deep and ultrasonic pulses travel the long distance (especially more than 1,500 meters), a standard of judgement on fish traces changes. In this survey, operations referred to are limited to those in depths of 150 to 320 meters.

The area of fish school having entered the net on the recording paper is calculated as shown in Fig. 6. Area $F$ of the fish traces obtained by Net recorder is substituted by equivalent $a \times c$ and $F^{\prime}$ by $a^{\prime} \times c^{\prime}$ and so on. Then these areas are integrated. 


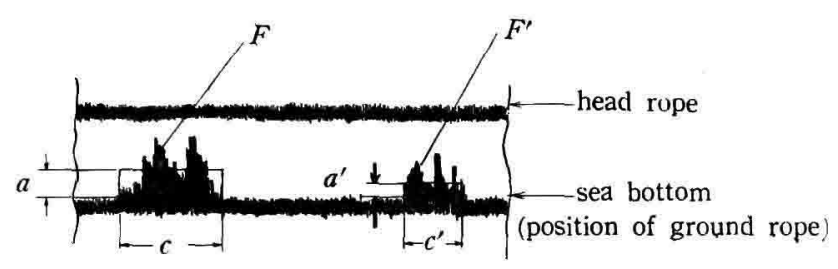

Fig. 6. Calculation method for integrating the area of fish traces.

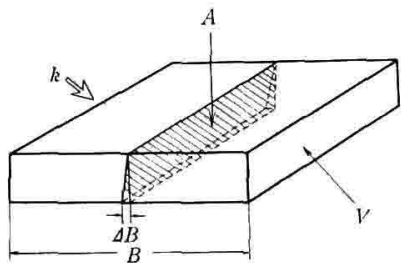

Fig. 7. The relation between the integrated area (A) and the haul of fish (V).

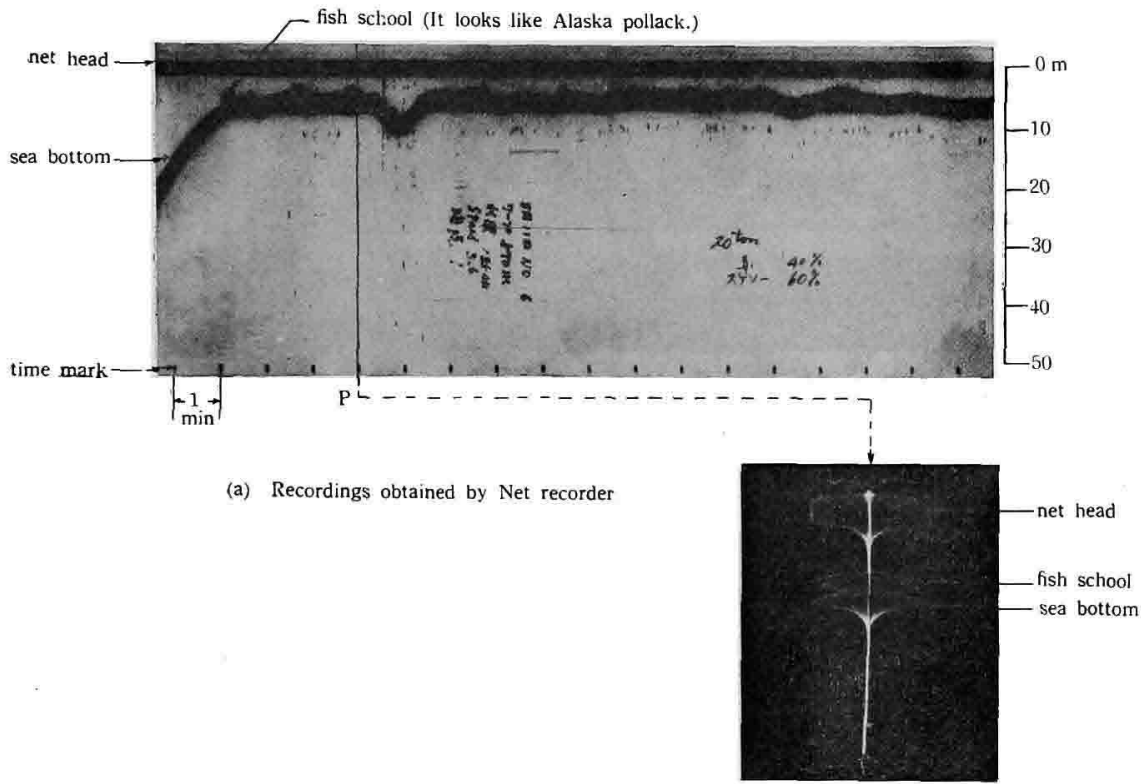

(b) Trace of $\mathrm{P}$ line obtained by CRT

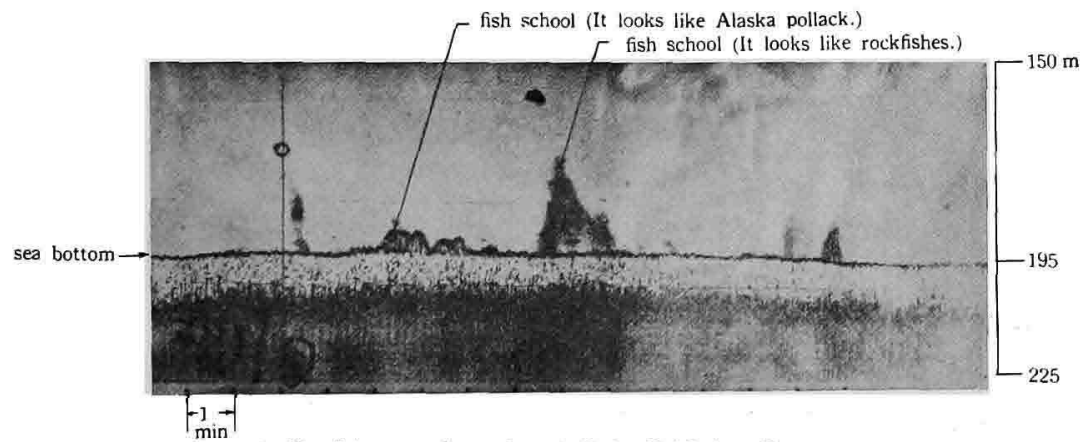

(c) The fish traces detected vertically by Fishfinder. Frequency of ultrasonic waves is $28 \mathrm{kc}$ s.

Fig. 8. The recordings obtained by Net recorder and Fish finder at the same position on 11th August. The amount of fish is 20 tons (rockfishes: 8 tons, Alaska pollack: 12 tons). Ship's speed: $3.6 \mathrm{kts}$. 


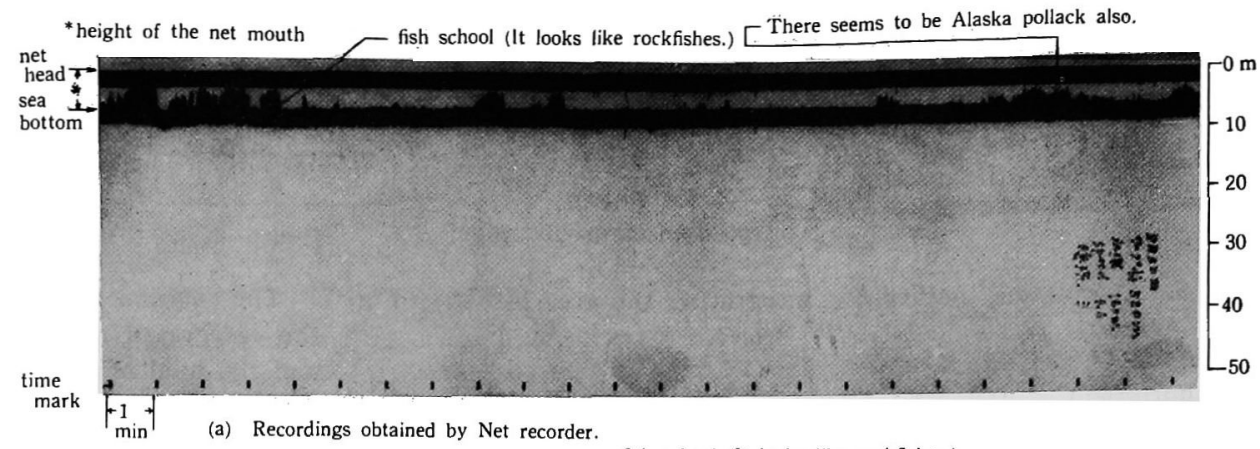

(a) Recordings obtained by Net recorder.

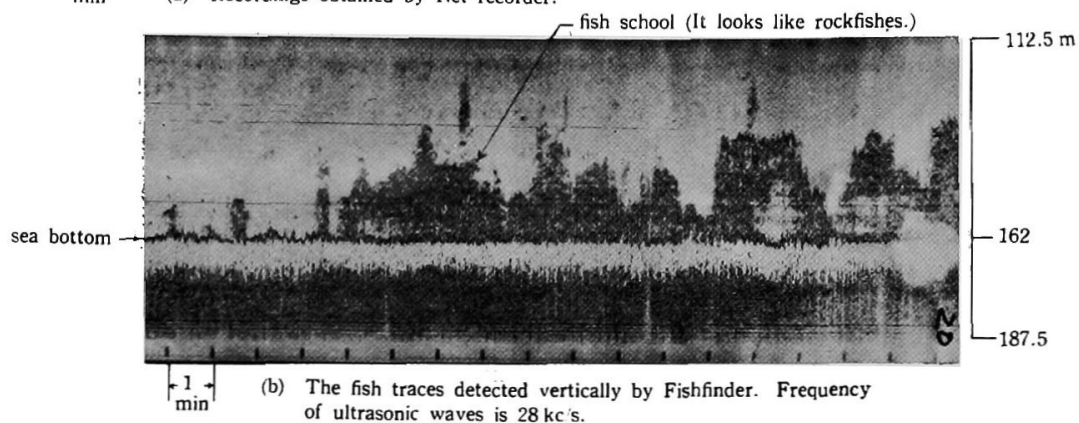

Fig. 9. The recordings obtaind by Net recorder and Fish finder at the same position on 30th August. The amount of fish is 30 tons (rockfishes: 21 tons, Alaska pollack: 9 tons). Ship's speed: $3.6 \mathrm{kts}$.
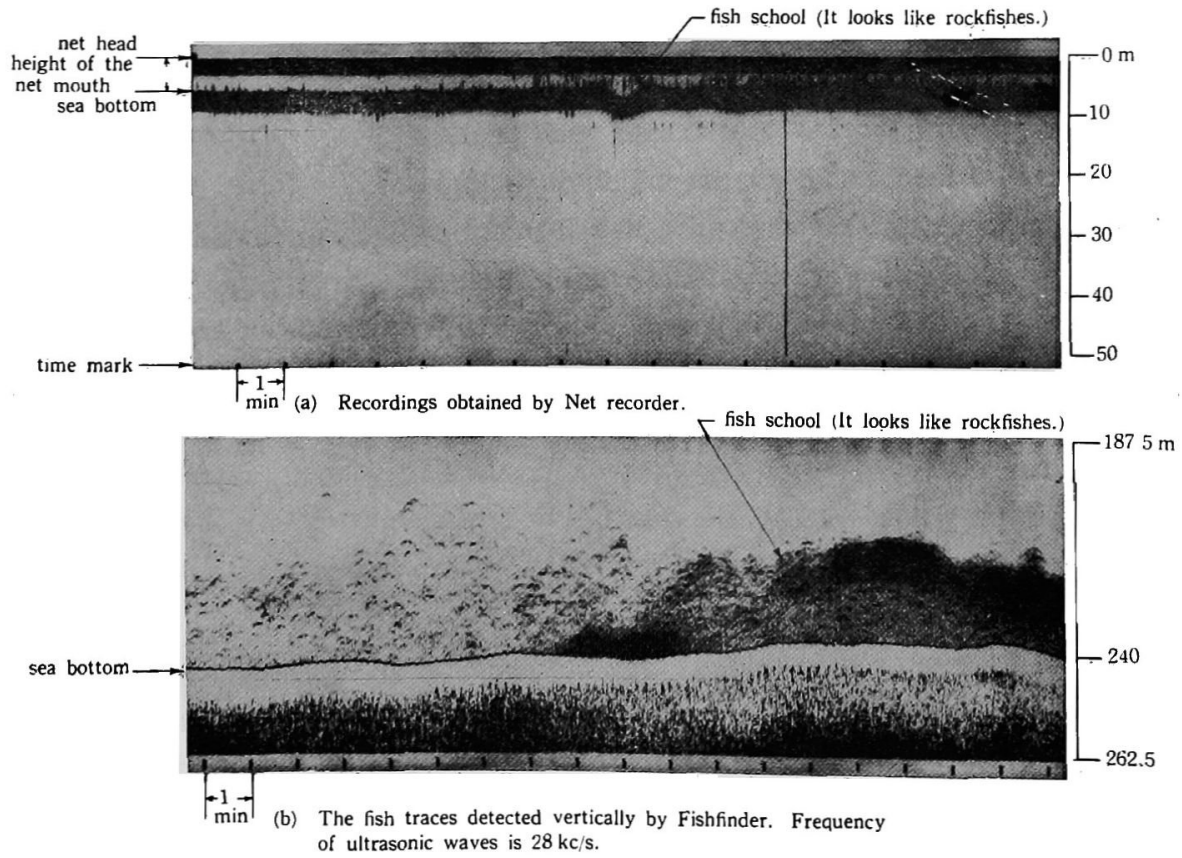

Fig. 10. The recordings obtained by Net recorder and Fish finder at the same position on 4th September. The amount of fish is 18 tons (rockfishes: 14.5 tons, Alaska pollack: 3.5 tons). Ship's speed: 3.6 kts. 
Darkness on the recordings of fish school varies according to density of fish school. But as the darkness is also changed by the water depth of fish school, it is not taken into consideration in this report. Regarding the compensation for boat's speed, as the boat was trawling almost always at the speed of 3.6 knots, the calculations are based on this speed.

As shown in Fig. 7, the range detected by ultrasonic pulses emitted from the detector part is very narrow, since the directivity of them is very sharp and detectable range is very short. Supposing $A$ to be the integrated area, there is the following relationship between the integrated area $A$ and the haul of fish $V$ :

$$
k \cdot A \cdot B=V
$$

where $k$ is a constant for number of fish per unit volume. This shows that as the width of the net mouth $B$ is constant, the integrated area of the fish traces is on a linear relation to the fish catch.

Table 1 based on the data collected in this survey shows the integrated area of fish traces, haul of fish, species of fish, depth of operation, boat's speed, time of operation, etc. Rockfishes, Sebastes s.p., and Alaska pollack, Theragra chalcogramma, were proved to be 30 to $40 \mathrm{~cm}$ in total length. Alaska pollack was still in its youth.

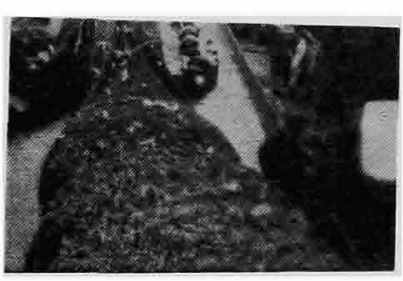

Fig. 11. Fish which were caught when the recording shown in Fig. 9 was obtained.

Figs. $8-10$ show the recordings obtained by Net recorder used in this survey and the recordings of the near sea bottom obtained at the same position by Fish finder. In the recordings of fish school, species of fish presumed are written down. Fig. 11 shows the amount of fish at the time of hauling when the recording shown in Fig. 9 was obtained. In these figures, only three examples were cited, but characteristic relationship between the species of fish and the fish traces appeared on Net recorder was also examined on the basis of all the data, which will be mentioned in the next part.

\section{Results}

Fig. 12 is a graph showing the relation between the haul of fish (ton) and the integrated area $\left(\mathrm{mm}^{2}\right)$ of fish traces based on the data of Table 1 and line (1) shows that the integrated area is approximately proportional in linearity to the haul of fish. This enables us to determine the towing time required by examining the recordings of fish entering the net.

As shown in Fig. 12, the dots are scattered and this scattering owes to several reasons, one of which is that rockfishes and Alaska pollack exist at different proportion per haul of fish. When the haul of fish is constant and the proportion of rockfishes in a haul of fish is larger than that of Alaska pollack, the integrated area of fish 


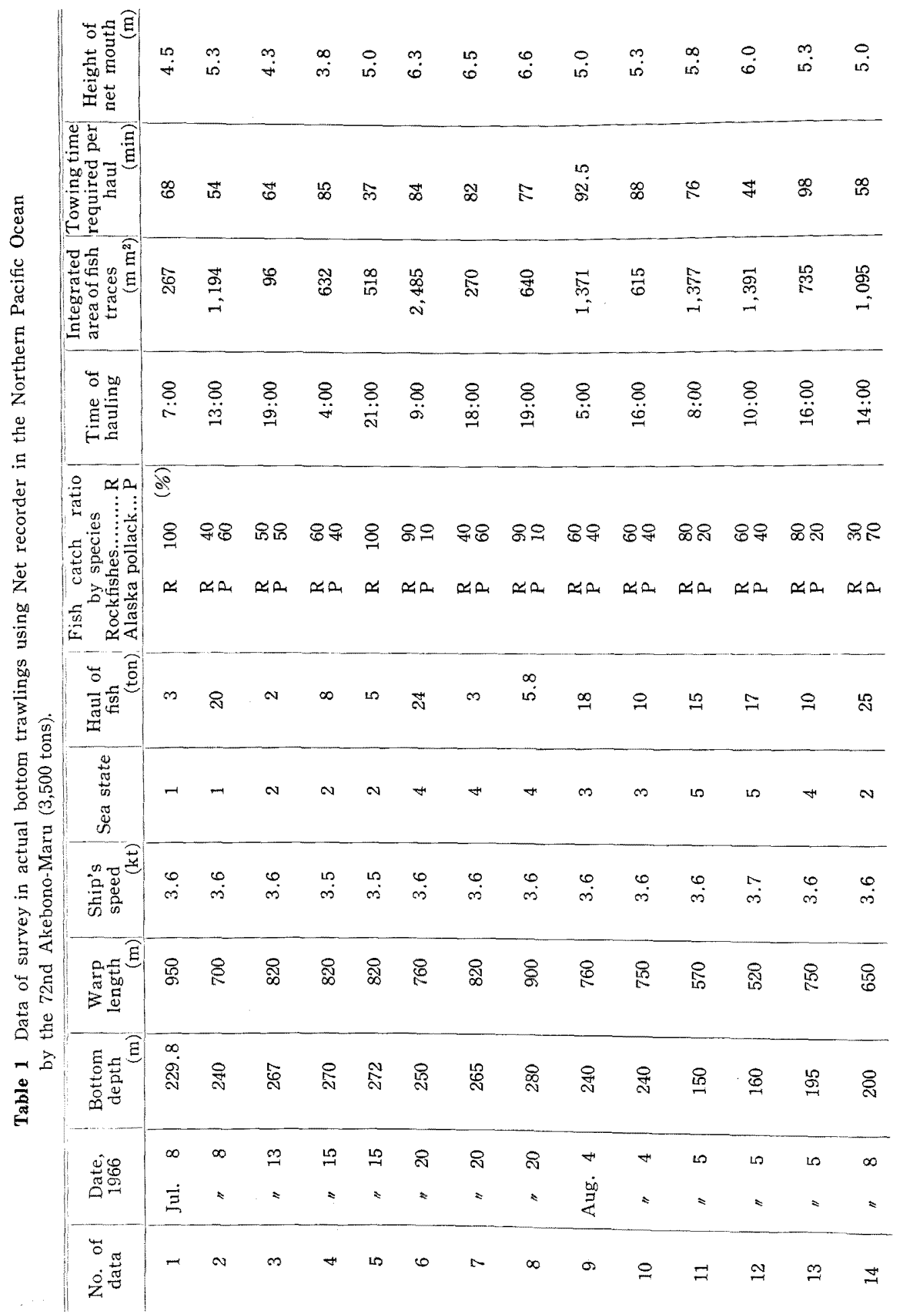




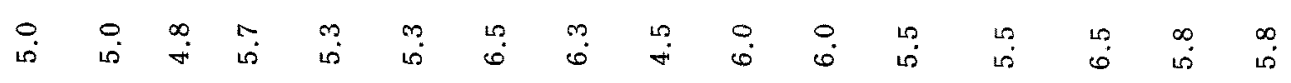

ค

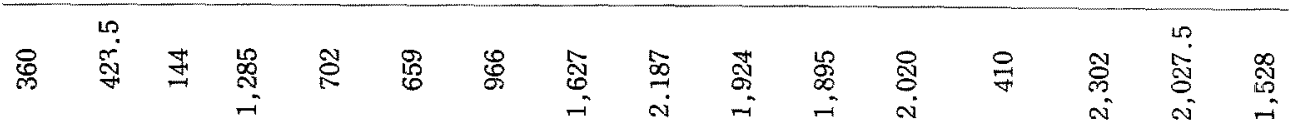

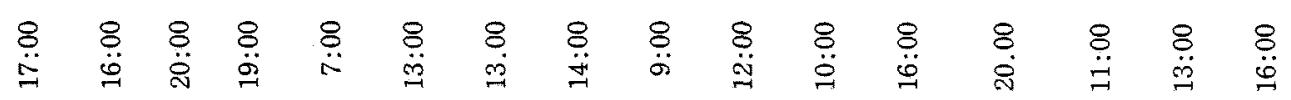

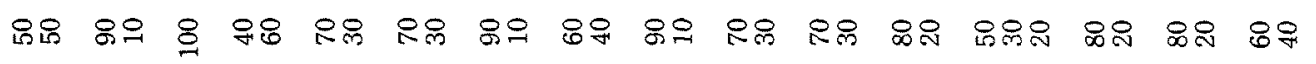

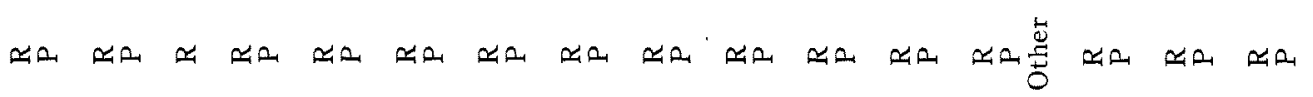
เ

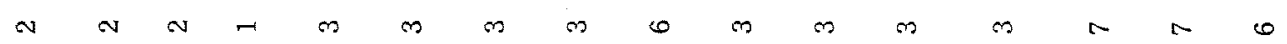

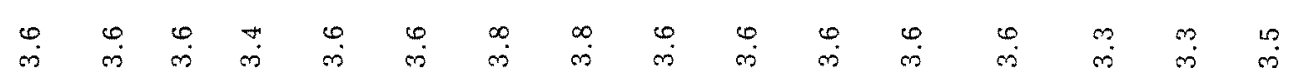

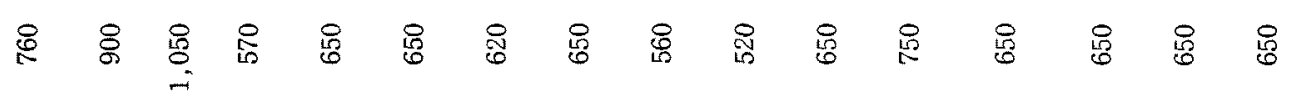

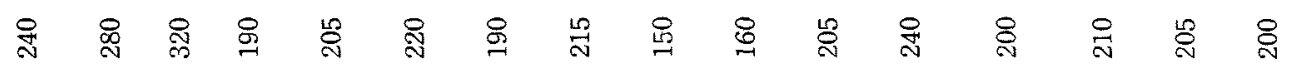

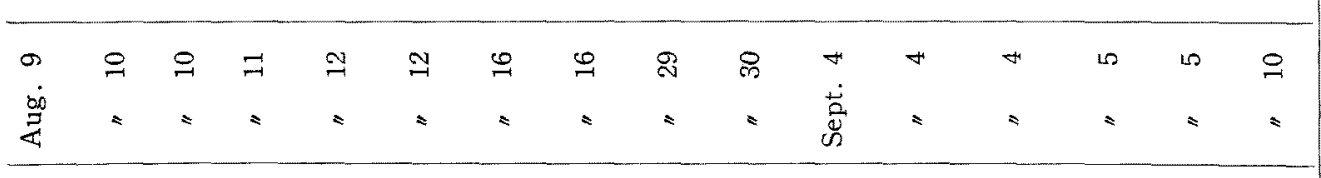

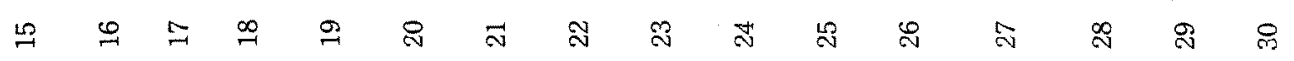


(3)

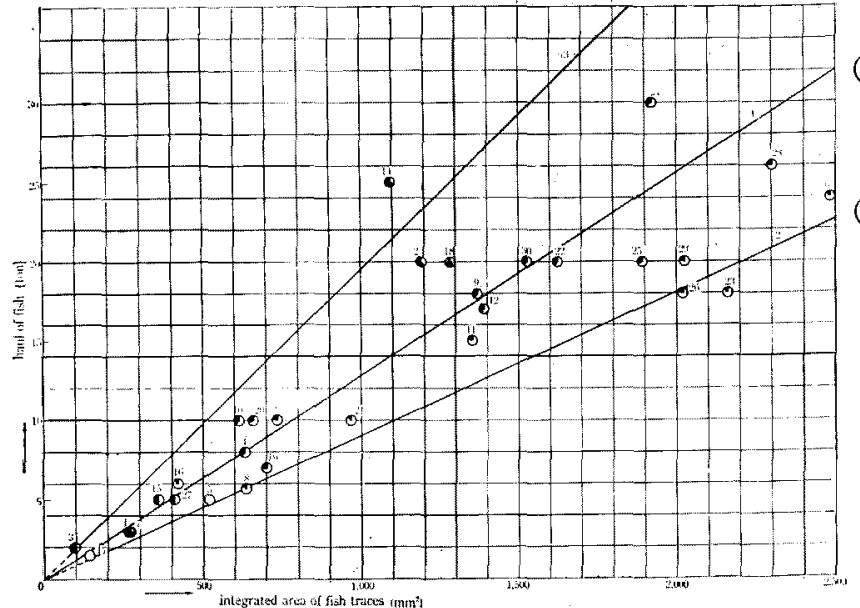

Fig. 12. The relation between the haul of fish (ton) and the integrated area $\left(\mathrm{mm}^{2}\right)$.

Rockfishes.

- Alaska pollack.

D Mixture of rockfishes and Alaska pollack.

Other fish.
(1)

(2)

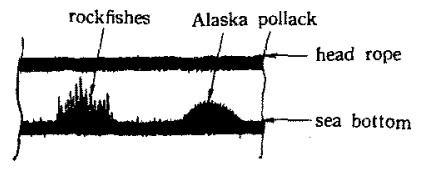

Fig. 13. Types of fish traces on the recordings of rockfishes and Alaska pollack.

school on the recordings has tendency to enlarge. On the other hand, in case the proportion of Alaska pollack is larger than that of rockfishes, the area are traced on the recording paper as rather small one. When rockfishes forms larger portion, the haul of fish is dotted on the right of the line (1). On the other hand, when Alaska pollack does, the haul of fish is dotted on the left side of the line (1). This means that even if the area of traces of rockfishes is equal to that of Alaska pollack, there is difference in density between them. Therefore, the equation (1) is replaced with the following:

$$
k_{r} \cdot a_{n} \cdot B+k_{c} \cdot b_{n} \cdot B=V
$$

where $k_{r}$ and $k_{c}$ are constants for number each of rockfishes and Alaska pollack per unit volume, $a_{n}$ and $b_{n}$ are areas of rockfishes and Alaska pollack based on given data. By inserting each data of Table 1 in the equation (2), the average ratio $\left(k_{r} / k_{c}\right)$ of density of rockfishes to that of Alaska pollack was $1 / 2$. This shows that the density of Alaska pollack is higher than that of rockfishes, i.e. 1 rockfishes to 2 Alaska pollack.

When the integrated area was obtained, supposing that the haul of fish consisted of rockfishes or Alaska pollack, the following tendency graphed in Fig. 12 was noticed: line (2) shows the haul consisted of $100 \%$ rockfishes and line (3) shows the haul of 100\% Alaska pollack.

Difference was observed between the traces of rockfishes and Alaska pollack on the recording paper, i.e. as shown in Fig. 13 as well as in Fig. 8 to 10 , rockfishes 
draws lengthways sharp traces almost touching the oscillation line (net head trace) and signals from Alaska pollack show densely sideways semicircular traces on the bottom line. Furthermore, experience of actual trawlings using Net recorder enabled us to distinguish the species of fish on the recordings. Based on the characteristic traces shown in Fig. 13, the integrated area of traces each of rockfishes and Ala. ska pollack was compared with the corresponding haul of fish and it was found that ratio $\left(k_{r} / k_{c}\right)$ of density of rockfishes to that of Alaska pollack was approximately $1 / 2$, which is almost equal to the ratio calculated on the basis of the data.

Additionally, the haul of fish every hour in a day was classified according to the 30 data of Table 1 as shown in Fig. 14. This shows that as generally

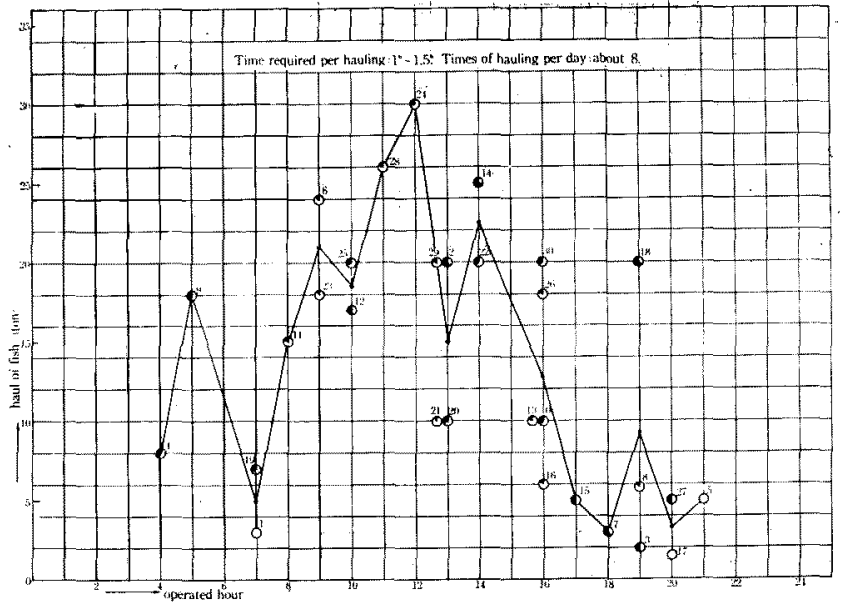

Fig. 14. The relation between the time of hauling and the haul of fish.

Rockfishes.

- Alaska pollack.

D Mixture of rockfishes and Alaska pollack.

Other fish.

known trawlings in daytime make bigger haul than those at night.

\section{Summary}

During 6th July through 12th September, 1966, actual trawlings using Net recorder were carried out by a large sized trawl boat in the fishery near Aleutian Islands and in the southern fishery of Alaska Peninsula in the Northern Pacific Ocean.

The following results which will be useful for bottom trawlings were concluded by comparing the recordings obtained by Net recorder showing the fish school having entered the net with the haul of fish correspond to the recordings. It is noted, however, that a large net (height of net mouth:5-6 m, width of it: $30 \mathrm{~m}$ ) was employed and that operations referred to in this survey are limited to those in depth of 150 to 320 meters.

1) It is presumed that the integrated area of fish traces obtained by Net recorder showing fish school entering the net is approximately proportional in linearity to the haul of fish correspond to the area. This means that Net recorder enables us to determine the towing time required by examining the recordings obtained by Net recorder. 
2) It is presumed that when both rockfishes and Alaska pollack are 30 to $40 \mathrm{~cm}$ in total length (Alaska pollack is in its youth), fish school of Alaska pollack is two times as dense as that of rockfishes.

3) Generally, rockfishes and Alaska pollack on the recordings obtained by Net recorder are distinguished, i.e. rockfishes draws lengthways sharp traces almost touching the oscillation line, while, Alaska pollack draws densely sideways semicircular traces on the bottom line.

The writers wish to express their gratitude to SHIBATA, chief of the Northern Pacific Ocean Trawling Department, and NaKaTA, chief fisherman of the 72nd Akebono-Maru, both of Nichiro Gyogyo Co., Ltd. for their instruction and co-operation. 